\title{
Correlation between nonverbal communication and objective structured clinical examination score in medical students
}

\author{
Seung Guk Park ${ }^{1}$ and Kyung Hye Park ${ }^{2}$ \\ ${ }^{1}$ Department of Family Medicine, Inje University College of Medicine, Busan and ${ }^{2}$ Department of Medical Education, \\ Yonsei University Wonju College of Medicine, Wonju, Korea
}

Purpose: Nonverbal communication (NVC) may be a crucial factor affecting effective communication between patients and medical students during the objective structured clinical examination (OSCE), but it has not been intensively studied. We examined NVC and its correlation with patient-physician interaction (PPI) in the OSCE.

Methods: A total of 68 video recordings of routine check-up OSCEs were included. A checklist for NVC was developed that included seven nonverbal factors in a mute state (NVM) and four nonverbal factors in speech (NVS), and one point was assigned to each factor. The scores for history taking, PPI, NVM, and NVS were compared, and correlations of each score were evaluated.

Results: Students with adequate facial expressions, accorded speech rate and voice volume, adequately matched voice tone, and few or no moments of unnecessary silence showed better PPI scores. The PPI score was correlated with history taking and the NVS score, but not the NVM score.

Conclusion: Our results suggest that NVS may be more influential to PPI during OSCEs than NVM. Communication teachers should help students to be better prepared to use both NVS and NVM properly.

Key Words: Nonverbal communication, Patient satisfaction, Medical history taking, Medical student, Medical education

\section{Introduction}

Nonverbal behavior, tone of voice, and words are three basic elements of face-to-face communication [1]. According to Mehrabian [1], words, body language, and tone of voice account for $7 \%, 55 \%$, and $38 \%$ of effective communication, respectively. In other words, there are three components of communication: verbal, nonverbal observed in a mute state, and nonverbal speech. The verbal component, in which words are the content, occurs in a single mode. The nonverbal component can occur in several modes at once. Body language refers to nonverbal components observed in a mute state, such as facial expression, eye contact, gestures, touching, postural changes, and body position. On the other hand, tone of voice, speech rate, silence, and voice volume can be observed during speech, not in a mute state. Nonverbal components contribute to over $90 \%$ of effective communication and help the appropriate delivery of feelings and attitude [1,2].

Nonverbal behavior representing clinical warmth and
Received: February 1, 2018 • Revised: March 29, 2018 • Accepted: May 25, 2018 Corresponding Author: Kyung Hye Park (https://orcid.org/0000-0002-5901-6088) Department of of Medical Education, Yonsei University Wonju College of Medicine, 20 Ilsan-ro, Wonju 26426, Korea

Tel: +82.33.741.0242 Fax: +82.33.742.5034 email: erdoc74@gmail.com
Korean J Med Educ 2018 Sep; 30(3): 199-208.

https://doi.org/10.3946/kjme.2018.94

eISSN: 2005-7288

(C) The Korean Society of Medical Education. All rights reserved. This is an open-access article distributed under the terms of the Creative Commons Attribution Non-Commercial License (http:// creativecommons.org/licenses/by-nc/3.0/), which permits unrestricted non-commercial use, distribution, and reproduction in any medium, provided the original work is properly cited. 
listening influences patients' satisfaction, compliance, and clinical outcomes [3,4]. Effective nonverbal communication can convey empathy, caring, reassurance, and support to patients, but inappropriate nonverbal communication by the physician can convey disinterest and disbelief [5]. Patients are more satisfied with physicians attending to nonverbal behaviors: more eye contact, more leaning forward, more nodding and gestures, and closer interpersonal distance [6]. When an oncologist maintained more consistent eye contact, patients demonstrated better recall [7]. However, nonverbal communication is almost unavoidable and involuntary [8]. Although doctors know which behaviors improve rapport and facilitate positive patient outcomes, most people face difficulties changing their behavior [9]. Students also cannot immediately put theory into practice, because behaviors associated with nonverbal communication are employed unconsciously and automatically during communication [9]. Medical communication teachers should teach positive as well as negative nonverbal communication behaviors.

Nonverbal communication is also important between a medical student and a standardized patient (SP) in educational medical simulations. Insufficient nonverbal communication has proven to be the weakness of medical students that was most frequently described by SPs [10]. High satisfaction of SPs was more correlated with the nonverbal behavior score than with verbal communication [11]. In a previous study, adequate facial expression, affirmative gestures, and limited unpurposive movements had a positive effect on overall interview quality in the objective structured clinical examination (OSCE) [12]. Equal distribution of gaze toward the patient, adequate nodding, directly facing the patient, and accordance of speech rate and voice volume were correlated with high ratings given by SPs in OSCEs for post-clerkship medical students [13]. Previous studies on interaction between student doctors and SPs have focused more on verbal communication than nonverbal communication, and nonverbal communication was not separated into silent nonverbal communication and all sound-related elements independent of content [11-13]. Sound related nonverbal factors in particular have not been intensively studied. In contrast to verbal communication, nonverbal communication involves all components except for content.

The aim of this study, then, is to analyze both nonverbal factors in one OSCE and investigate its correlation with patient-physician interaction (PPI) in first-year medical students at a single medical college.

\section{Methods}

\section{Communication course and objective structured clinical examination}

A basic medical communication skills course has been part of the doctor competency development module for first-year medical students at Inje University since March 2016. Participants were first-year medical students, who had finished 2 years of premedical courses, in a 6-year program. The doctor competency development module consists of basic medical communication skills, basic physical examination skills, introduction to problembased learning, self-development of competence, and clinical reasoning. This module runs for consecutive 4 weeks. The basic communication skills course consists of six topics: medical interview experience, agenda setting, attentive listening, empathy, medical interview with pediatric patients, and patient education. Each topic is covered in a 4-hour class: (1) 1 hour of lecture, (2) 2 hours of exercises with SPs and formative feedback, and (3) 1 hour of discussion and summary with the instructor. 
Thus, the entire basic communication skills course is covered in 24 hours. During the 2-hour exercise with SPs, six to seven students meet with one SP. Each student takes a turn in the practice medical interview with an SP for 5 minutes. Feedback by the SP and student peers is provided to the student immediately after the interview.

Three stations of the OSCE are integrated into the course as a summative assessment: physical examination of the abdomen, physical examination of the heart, and an interview for a routine check-up. As the routine check-up is the only one in which communication skills are assessed, this station was selected for the present study. In this station, built-in video camera equipment and portable microphones were used for recording all exams. These recordings are made available for the remediation of students who fail to pass the communication OSCE.

A routine check-up case was developed by the medical communication committee at the Inje University College of Medicine, to evaluate basic communication skills. The case involves a 44-year-old female with a 5-minute interview for a regular check-up. The SPs learned to present their social background as well as their family and personal medical histories. They were also trained to provide specific answers to the questions expected of the student doctor according to the scenario and then rate the students' history taking and PPI; therefore, history taking and PPI were evaluated by SPs. History taking included four items, to be scored from 0 to 4 (for a total score of 0 to 16). PPI included five items and was also scored from 0 to 4 (for a total score of 0 to 20). The PPI rating scale used was the same as that of the marking sheet of the Busan-Gyeongnam Consortium [14].

\section{Participants}

A total of 102 students participated in the OSCE in
March 2016. First-year medical students were selected, because they can have immature or poorly trained nonverbal communication behaviors. Three female SPs were recruited for the examination, whose real ages were in their early fifties and who had more than 5-year experience as SPs. One SP at each station met 34 medical students.

From this sample, 68 video recordings were available for analysis. Three SPs were recruited for the interview for the routine check-up station; one SP in each station met 34 medical students. It was impossible to analyze nonverbal components for the rest of the students because their faces were blocked by the back of the SP's head in the video recordings from one station. Therefore, 68 students and two SPs from 68 video recordings were included.

The Institutional Review Board of Inje University approved the study (IRB approval no., Inje 2016-09011-001).

\section{Development of the nonverbal communi- cation analysis checklist}

In a previous study, "nonverbal communication" generally refers to eye contact, body and extremity movement, posture, facial expressions, voice tone, gestures, etc. [15]. In our study, a draft of the checklist was developed based on previous studies regarding nonverbal communication in medical encounters [11-13]. Hand gestures were excluded from nonverbal communication in this study, because the relationship between hand gesture and patient satisfaction was controversial in previous studies. SPs perceived better interview quality in OSCEs in which physicians and medical students used few or no hand gestures [12]. On the other hand, patient satisfaction was correlated with hand gestures in real medical encounters [6,11]. Burgoon et al. [5] reported that active gesturing generally signals affiliation, whereas expres- 
sive and expansive gesturing that fills space signals relaxed charismatic authority. Therefore, affirmative hand gestures appropriate to the conversation were classified as affirmative gestures.

The authors found that sudden awkward silences or giggling by students occurred during exercises with SPs when the students did not know what to say. The inadequate speech-related nonverbal behaviors of the first-year students could have been caused by immaturity during the medical interview with the SP. These two behaviors led to SPs perceiving the situation as awkward. Such phenomenon was named "moments of unnecessary silence, pauses of conversation" or "giggling." Since these cannot be observed in a mute state, they were classified as nonverbal factors in speech and added to the checklist (Table 1).
Since the authors expected each component to have different effects on PPI, both nonverbal factors were separately analyzed in our study. Nonverbal communication was divided into nonverbal factors in a mute state (NVM) and in speech (NVS). NVM was defined as eye contact, body and extremity movement, posture, and facial expression, which can be observed even by muting the video. NVS was defined as sound-related elements, not content: speech rate, voice volume, silence, and giggling, which cannot be observed by muting the videos but only when the audio is on. In fact, the authors did not watch the video in mute to observe NVM, because NVM and NVS should be checked simultaneously.

Environmental cues are one form of nonverbal communication. Since the medical encounter of this study was summative examination, all medical students

Table 1. Nonverbal Factors in a Mute State and in Speech, and Their Examples

\begin{tabular}{|c|c|c|c|}
\hline Category & Score $=0$ & Score $=1$ & Examples \\
\hline \multicolumn{4}{|l|}{$\begin{array}{l}\text { Nonverbal factors in a mute } \\
\text { state }\end{array}$} \\
\hline Facial expression & Blank or mismatched & Adequately expressive & \\
\hline Eye contact & More likely when talking & $\begin{array}{l}\text { Equal when talking and } \\
\text { listening }\end{array}$ & \\
\hline Affirmative gestures & Infrequent & Adequately frequent & $\begin{array}{l}\text { Head nodding, smiling, hand gestures in } \\
\text { accordance with the context of } \\
\text { conversation }\end{array}$ \\
\hline $\begin{array}{l}\text { Self-touching or unpurposive } \\
\text { movements }\end{array}$ & Frequent & Few or none & $\begin{array}{l}\text { Touching the face, twirling a pen, } \\
\text { manipulating objects }\end{array}$ \\
\hline Postural change & Yes & No & $\begin{array}{l}\text { If a student shifted body lean or posture } \\
\text { at the point of the communication challenge } \\
\text { issued by the standardized patient. }\end{array}$ \\
\hline Body lean & $\begin{array}{l}\text { Backward to the chair, } \\
\text { touching the back of the } \\
\text { chair }\end{array}$ & $\begin{array}{l}\text { Neutral or forward to the } \\
\text { patient }\end{array}$ & \\
\hline Body position & Closed & Open & $\begin{array}{l}\text { Closed: crossed arms, angled away from } \\
\text { the patient }\end{array}$ \\
\hline \multicolumn{4}{|l|}{ Nonverbal factors in speech } \\
\hline Speech rate and voice volume & Not accorded & Accorded & $\begin{array}{l}\text { Patient-doctor accordance of speech rate } \\
\text { and voice volume }\end{array}$ \\
\hline $\begin{array}{l}\text { Match of voice tone with verbal } \\
\text { contents }\end{array}$ & Flat & Adequate & $\begin{array}{l}\text { Match of voice tone and intonation with } \\
\text { the verbal contents }\end{array}$ \\
\hline $\begin{array}{l}\text { Moments of unnecessary } \\
\text { silence, pauses of } \\
\text { conversation }\end{array}$ & Frequent & Few or none & \\
\hline Giggle & Frequent & Few or none & \\
\hline
\end{tabular}


met SPs in well-controlled and consistent environments and conditions. Therefore, environmental cues (e.g., noise) were not considered in this study.

Finally, a total of 11 items were defined, including seven NVM and four NVS. One point was assigned to each item if it was appropriate, and 0 point was assigned if it was not, and the scores for each item were summed up to form a total score. The range of the total NVM score was $0-7$, and the range of the total NVS score was $0-4$, with higher scores indicating better performance.

The authors randomly chose five samples of recordings to evaluate inter-rater reliability. One author (KHP) was an emergency physician who had taught basic medical communication skills for 4 years. The other author (SGP) was a family medicine physician who had taught for 5 years. The two authors independently rated samples according to a checklist by watching the video recordings. If the two raters disagreed in their ratings, they discussed the issue to reach an agreement, watching the video recordings again.

\section{Data analysis}

All continuous variables were described as median values and interquartile range. There were two groups in each of the factors, defined as score 1 group (appropriate NVM or NVS) and score 0 group (inappropriate NVM or NVS). The scores of history taking, PPI, NVM, and NVS were compared between the two groups in each item using a Mann-Whitney U-test. Spearman correlation analysis was used to investigate correlation among scores of history taking, PPI, NVM, and NVS. The IBM SPSS ver. 20.0 (IBM Corp., Armonk, USA) was used for the analyses, and significance was declared at $\mathrm{p}<0.05$.

\section{Results}

\section{Inter-rater reliability}

The inter-rater reliability, in terms of the gamma coefficient, was 0.897 on average (range, 0.55-1.00).

\section{Nonverbal factors in a mute state}

We compared the history taking score, the PPI score, and the NVS score by separating the group with 1 point and the group with 0 point for each item of NVM. Since the body leaning of all students was neutral or forward, it was excluded from comparison. There were 64 students with adequate facial expression, and they showed a significantly higher score in history taking, PPI, and NVS than did the four students with mismatched facial expression (Table 2).

A total of 17 students were more likely to use eye contact when talking than when talking and listening. They looked at instructions for the OSCE station or made medical notes while the SP was talking. However, there was no difference in history taking score, PPI score, and NVS score between the two groups. In addition, 64 students with adequate and frequent affirmative gestures showed better NVS scores than did the four students with infrequent affirmative gestures. However, there were no differences in history taking score, PPI score, and NVS score for the items of eye contact, unpurposive movements, postural change, and body position (Table 2). Particularly, about half of the students still showed unpurposive movements, even in the summative assessment.

Although most students demonstrated adequate nonverbal behaviors, only one showed postural change, and about half had unpurposive movements, such as touching one's own face or hair, twirling a pen, or manipulating objects (Table 2). 
Table 2. Comparison of Nonverbal Factors in a Mute State

\begin{tabular}{|c|c|c|c|}
\hline Variable & Score $=0$ & Score $=1$ & p-value \\
\hline Facial expression & Blank or mismatched $(n=4)$ & Adequately expressive $(n=64)$ & \\
\hline History taking score & $4.00(1.00-7.00)$ & $8.00(8.00-12.00)$ & 0.017 \\
\hline PPI score & $6.00(5.25-7.50)$ & $12.00(9.00-13.00)$ & 0.002 \\
\hline NVS score & $2.00(1.25-2.75)$ & $4.00(4.00-4.00)$ & 0.000 \\
\hline Eye contact & More likely when talking $(n=17)$ & Equal when talking and listening $(n=51)$ & \\
\hline History taking score & $8.00(4.00-9.00)$ & $8.00(8.00-12.00)$ & 0.123 \\
\hline PPI score & $11.00(8.00-13.50)$ & $11.00(9.00-13.00)$ & 0.648 \\
\hline NVS score & $4.00(3.00-4.00)$ & $4.00(4.00-4.00)$ & 0.095 \\
\hline Affirmative gestures & Infrequent $(n=4)$ & Adequately frequent $(n=64)$ & \\
\hline History taking score & $8.00(8.00-11.00)$ & $8.00(5.00-12.00)$ & 0.891 \\
\hline PPI score & $7.50(5.50-11.75)$ & $11.50(9.00-13.00)$ & 0.064 \\
\hline NVS score & $3.00(2.25-3.75)$ & $4.00(4.00-4.00)$ & 0.002 \\
\hline Unpurposive movements & Frequent $(n=35)$ & Few or none $(n=33)$ & \\
\hline History taking score & $8.00(8.00-12.00)$ & $8.00(6.00-12.00)$ & 0.802 \\
\hline PPI score & $12.00(9.00-13.00)$ & $11.00(8.00-13.00)$ & 0.634 \\
\hline NVS score & 4.00 (4.00-4.00) & 4.00 (4.00-4.00) & 0.716 \\
\hline Postural change & Yes $(n=1)$ & No $(n=67)$ & \\
\hline History taking score & $4.00(4.00-4.00)$ & $8.00(8.00-12.00)$ & 0.182 \\
\hline PPI score & 9.00 (9.00-9.00) & 11.00 (9.00-13.00) & 0.488 \\
\hline NVS score & $4.00(4.00-4.00)$ & $4.00(4.00-4.00)$ & 0.662 \\
\hline Body position & Closed $(n=4)$ & Open $(n=64)$ & \\
\hline History taking score & $6.00(4.00-11.00)$ & 8.00 (8.00-12.00) & 0.326 \\
\hline PPI score & 8.00 (7.25-11.75) & $11.50(9.00-13.00)$ & 0.121 \\
\hline NVS score & $4.00(4.00-4.00)$ & 4.00 (4.00-4.00) & 0.371 \\
\hline
\end{tabular}

Data are presented as median (interquartile range).

PPI: Patient-physician interaction, NVS: Nonverbal factors in speech.

Table 3. Comparison of Nonverbal Factors in Speech

\begin{tabular}{lcrc}
\hline \multicolumn{1}{c}{ Variable } & Score $=0$ & Score=1 & p-value \\
\hline Speech rate and voice volume & Not accorded $(n=5)$ & Accorded $(n=63)$ & 0.006 \\
History taking score & $4.00(2.00-6.00)$ & $8.00(8.00-12.00)$ & 0.000 \\
PPI score & $6.00(5.50-7.00)$ & $12.00(9.00-13.00)$ & 0.123 \\
NVM score & $5.00(3.00-5.50)$ & $5.00(5.00-6.00)$ & 0.051 \\
Match of voice tone & Flat $(n=3)$ & Adequate $(n=65)$ & 0.009 \\
History taking score & $4.00(0.00-8.00)$ & $8.00(8.00-12.00)$ & 0.058 \\
PPI score & $6.00(5.00-8.00)$ & $12.00(9.00-13.00)$ & $5.00(5.00-6.00)$ \\
NVM score & $5.00(2.00-5.00)$ & Few or none $(n=59)$ & 0.001 \\
Unnecessary silence & Frequent $(n=9)$ & $8.00(8.00-12.00)$ & 0.001 \\
History taking score & $4.00(4.00-8.00)$ & $12.00(9.00-14.00)$ & 0.086 \\
PPI score & $8.00(6.00-9.50)$ & $5.00(5.00-6.00)$ & 0.104 \\
NVM score & $5.00(4.50-5.50)$ & Few or none $(n=67)$ & 0.085 \\
Giggle & Frequent $(n=1)$ & $8.00(8.00-12.00)$ & 0.246 \\
History taking score & $16.00(16.00-16.00)$ & $11.00(9.00-13.00)$ & $5.00(5.00-6.00)$ \\
PPI score & $16.00(16.00-16.00)$ & $6.00(6.00-6.00)$ & \\
NVM score & & & \\
\hline
\end{tabular}

Data are presented as median (interquartile range).

PPI: Patient-physician interaction, NVM: Nonverbal factors in a mute state. 
Fig. 1. Correlation among Scores

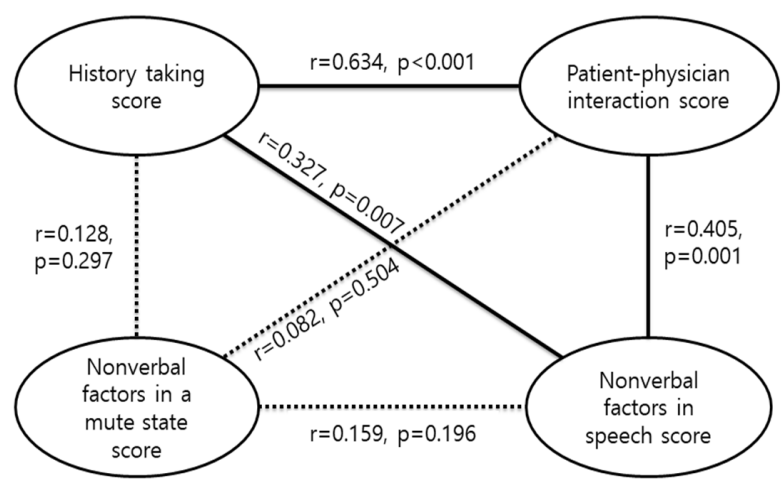

A solid line indicates significant correlation, and a dotted line indicates no correlation in Spearman correlation analysis.

\section{Nonverbal factors in speech}

Sixty-three students with accorded speech rate and voice volume had better history taking scores and PPI scores than their counterparts. Students with adequately matched voice tone had better PPI scores than their counterparts. Students having little or no unnecessary silence had better history taking scores and PPI scores than their counterparts. There was no difference in giggling between the groups (Table 3).

\section{Correlation among scores of history taking, patient-physician interaction, nonverbal factors in a mute state and in speech}

PPI score was positively correlated with the history taking score and NVS score. In addition, the history taking score was also positively correlated with NVS score. NVM score was not correlated with history taking score, PPI score, or NVS score (Fig. 1).

\section{Discussion}

We demonstrated that students with adequate facial expression, accorded speech rate and voice volume, adequately matched voice tone, and little or no unneces- sary silence had better PPI scores than their counterparts. PPI score was correlated with NVS score, not NVM score.

Adequate facial expression by medical students was associated with good interview quality, because these students had better scores in history taking, PPI, and NVS. Facial movements comprise a dense source of nonverbal cues by revealing expressivity from mouth to brow. A pleasing and smiling expression indicates openness, and quiet dignity; it positively reinforces interaction between patients and physicians [5]. However, in Japanese studies, facial expressivity was not associated with SP ratings due to less engagement by Japanese people in nonverbal immediacy behaviors [13]. The influence of facial expression might differ between countries and between the East and West. The authors believe that appropriate facial expression can have a significant influence on PPI, since the SP looks continuously at the face of the student during the OSCE. Additionally, students with good facial expression might have advantages when taking the OSCE.

Affirmative gestures were almost completely limited to the face: nodding and smiling. Therefore, adequate facial expressions and frequently adequate affirmative gestures were not inextricable. In our study, the students with adequate affirmative gestures did not show a difference in PPI score, but they had better NVS scores. Previous studies revealed that nodding and smiling by the physician were correlated with patient satisfaction and the physician's perceived friendliness $[6,7,13,16]$. Clinicians' use of gesture can enhance patients' memory of medical information [17].

PPI scores did not differ according to eye contact score. Consistent with our study, Mast et al. [16] reported that there was no correlation between looking at a patient's chart and patient satisfaction. However, in several previous studies, frequent eye contact and less 
time reading the medical chart improved SP or real patient satisfaction and were associated with higher perceived friendliness and better information recognition $[6,7,11,13]$. The SPs of our study might have given more weight to facial expression than eye contact.

No students leaned backward, and only one student had a frequent giggle. This might be because they were nervous during the OSCE and tried to maintain decorum for the SPs. However, about half of the students still unconsciously demonstrated unpurposive movements, even after six rounds of exercises with feedback by SPs. Therefore, frequent feedback or formative assessment of communication, using a nonverbal communication checklist for more constructive feedback, is necessary to improve nonverbal behavior.

The authors expected that inadequate NVS would have significant effects on PPI. Three items of NVS were correlated with good PPI: accorded speech rate and voice volume, adequately matched voice tone, and little or no unnecessary silence. Several studies have demonstrated that NVS and patient satisfaction are highly correlated. Accorded speech rate and voice volume were associated with higher ratings by SPs, after controlling for the quality of interview content [13]. Regarding tone of voice, a higher dominance tone of voice in surgeons is associated with malpractice claims history [18], whereas non-dominant tone of voice is related to patient satisfaction [19]. Moreover, vocal variety is a cue for trustworthiness that increases attention and rapport, enhancing patient comprehension or satisfaction $[5,16,17]$.

The students with little or no unnecessary silence had better history taking scores and PPI scores. The use of pauses during medical encounters is important and depends on the conversation process. Fewer pauses and proper response latencies have been associated with patient-clinician involvement and rapport [17]. However, too much silence during a medical interview risks conveying a sense of threat or intimidation, a lack of acknowledgement, and a reinforcement of power [5].

Students with higher NVS scores had higher history taking scores and PPI scores, which means that good NVS lead to good SP satisfaction, namely as it regards PPI, but NVM do not have the same effect. Moreover, regarding the history taking score, even though the OSCE case was just a regular check-up, students with better NVS could have better clinical reasoning skills. This finding requires further study. Obviously, NVM are important for medical communication, but NVS should also be emphasized.

This study had a few limitations. First, the sample size was small. Only first-year students of a single medical college were included. In addition, the analysis was limited to only one case. Moreover, PPI is influenced greatly by nonverbal communication as well as verbal communication, but verbal communication skills were not evaluated in this study. Students with better history taking scores showed better PPI scores and NVS scores. However, psychosocial communication such as facilitation and empathy expression were not analyzed in this study.

Since our study divided nonverbal communication into NVM and NVS, it is distinct from previous studies and, therefore, contributes to the literature. Dividing nonverbal communication into NVM and NVS is helpful for teaching medical communication to medical students. In addition, the checklist of nonverbal communication in this study can be used to give feedback to student doctors and to evaluate their nonverbal communication.

\section{ORCID:}

Seung Guk Park: https://orcid.org/0000-0002-2986-3729; Kyung Hye Park: https://orcid.org/0000-0002-5901-6088 Acknowledgements: None.

Funding: This work was supported by the Yonsei University 
Wonju Campus Future-Leading Research Initiative of 2017 (RMS2 2017-52-0067).

Conflicts of interest: No potential conflict of interest relevant to this article was reported.

Author contributions: Conception or design of the work: KHP; data collection: SGP, KHP; data analysis and interpretation: SGP, KHP; drafting the article: KHP; critical revision of the article: SGP; and final approval of the version to be published: KHP.

\section{References}

1. Mehrabian A. Silent messages: a wealth of information about nonverbal communication (body language). http:/ www.kaaj.com/psych/smorder.html. Accessed October 19, 2016.

2. Ranjan P, Kumari A, Chakrawarty A. How can doctors improve their communication skills? J Clin Diagn Res. 2015;9(3):JE01-JE04.

3. Henry SG, Fuhrel-Forbis A, Rogers MA, Eggly S. Association between nonverbal communication during clinical interactions and outcomes: a systematic review and metaanalysis. Patient Educ Couns. 2012;86(3):297-315.

4. Roter DL, Frankel RM, Hall JA, Sluyter D. The expression of emotion through nonverbal behavior in medical visits: mechanisms and outcomes. J Gen Intern Med. 2006;21 Suppl 1:S28-S34.

5. Burgoon JK, Guerrero LK, Floyd K. Nonverbal communication. Boston, USA: Pearson; 2010.

6. Hall JA, Harrigan JA, Rosenthal R. Nonverbal behavior in clinician-patient interaction. Appl Prev Psychol. 1995; 4(1):21-37.

7. Hillen MA, de Haes HC, van Tienhoven G, et al. Oncologists' non-verbal behavior and analog patients' recall of information. Acta Oncol. 2016;55(6):671-679.

8. Kurtz S, Silverman J, Draper J. Running a session: introducing research and theory; expanding and consolidating learning. In: Kurtz S, Silverman J, Draper J, eds. Teaching and Learning Communication Skills in Medicine. 2nd ed. Abingdon, UK: Radcliffe Publishing Ltd.; 2009:195-196.

9. Nicholson S, Cushing A. The importance of non-verbal behaviour: issues for selection, training and assessment. Med Educ. 2013;47(9):858-860.

10. Lee YH, Lee YM, Kim BS. Content analysis of standardized-patients' descriptive feedback on student performance on the CPX. Korean J Med Educ. 2010; 22(4):291-301.

11. Griffith CH 3rd, Wilson JF, Langer S, Haist SA. House staff nonverbal communication skills and standardized patient satisfaction. J Gen Intern Med. 2003;18(3):170174.

12. Collins LG, Schrimmer A, Diamond J, Burke J. Evaluating verbal and non-verbal communication skills, in an ethnogeriatric OSCE. Patient Educ Couns. 2011;83(2): 158-162.

13. Ishikawa $H$, Hashimoto $H$, Kinoshita $M$, Fujimori $S$, Shimizu T, Yano E. Evaluating medical students' nonverbal communication during the objective structured clinical examination. Med Educ. 2006;40(12):1180-1187.

14. Im S, Kim DK, Kong HH, Roh HR, Oh YR, Seo JH. Assessing clinical reasoning abilities of medical students using clinical performance examination. Korean J Med Educ. 2016;28(1):35-47.

15. Berman AC, Chutka DS. Assessing effective physicianpatient communication skills: "are you listening to me, doc?” Korean J Med Educ. 2016;28(2):243-249.

16. Mast MS, Hall JA, Köckner C, Choi E. Physician gender affects how physician nonverbal behavior is related to patient satisfaction. Med Care. 2008;46(12):1212-1218.

17. Buller DB, Street RL. Physician-patient relationships. In: Feldman RS, ed. Applications of Nonverbal Theories and Research. London, UK: Psychology Press; 1992:119-141. 
18. Ambady N, Laplante D, Nguyen T, Rosenthal R, Chaumeton N, Levinson W. Surgeons' tone of voice: a clue to malpractice history. Surgery. 2002;132(1):5-9.
19. Mast MS. On the importance of nonverbal communication in the physician-patient interaction. Patient Educ Couns. 2007;67(3):315-318. 